Anuario de Estudios Americanos, 71, 2

Sevilla (España), julio-diciembre, 2014, 507-537

ISSN: 0210-5810. DOI: 10.3989/aeamer.2014.2.05

\title{
La rebelión indígena de 1693: desnaturalización, violencia y comercio en la frontera de Chile/
}

The Indian Rebellion of 1693:

Banishment, Violence and Trade

in the Frontier of Chile

Sebastián Leandro Alioto

Universidad Nacional del Sur, Argentina

En 1693, una rebelión indígena puso en vilo a la estructura colonial hispana en el centro-sur chileno. En este artículo se examinan los motivos que impulsaron a los indios y que eran al menos dos: el principal, las recurrentes desnaturalizaciones dispuestas por el gobernador Tomás Marín de Poveda; el segundo, la monopolización del comercio fronterizo en manos del gobernador y sus dependientes, que generó perjuicio y descontento tanto a los nativos como a los comerciantes españoles.

Palabras Clave: Rebelión indígena; Desnaturalización; Comercio; Frontera; Chile.

In 1693, an Indian rebellion put in suspense the Spanish colonial structure in the Chilean central-southern region. This article examines the reasons the Indians had, which are at least two: the main one, the recurrent Banishments or desnaturalizaciones de indios decided by the governor Tomás Marín de Poveda. The second one, the monopolization of frontier trade in the hands of the governor and his collaborators, which generated prejudice and discontent both to natives and to Spanish traders.

KEYwORDS: Indian rebellion; Banishment; Trade; Frontier; Chile. 


\section{SEBASTIÁN LEANDRO ALIOTO}

... con el embeleco de sacar ocho o dies que dijeron ser brujos sacaron mas de sesenta criaturas de sus familias que aumentan con sus lagrimas las humedades deste pueblo. ${ }^{1}$

... como el amor de la patria es tan dulce i tan connatural, sienten mucho el dejarla, y mucho mas el mal recibimiento que hallan en los dueños de las tierras ajenas, que ya les quitan las mujeres, ya las hijas, i les obligan a rozar los montes por escojer para si los mejores valles. ${ }^{2}$

En el año de 1693, casi un siglo después del gran levantamiento indígena que destruyó las siete ciudades españolas de la Araucanía, ${ }^{3}$ y media centuria después de que las paces de Quillín (1641) pusieran provisorio fin a la Guerra de Chile iniciada con aquel, una nueva rebelión indígena puso en vilo a la estructura colonial hispana en la región centro-sur chilena.

La rebelión se fue gestando durante un tiempo, y tuvo varias causas confluyentes que se reforzaron entre sí; su estudio nos aparta de la visión tradicional e hispanófila que tuvo de ella Diego Barros Arana en su obra clásica sobre la historia chilena, en la cual adjudicó el conflicto a la inconstancia y barbarie de los nativos. ${ }^{4}$ La primera y quizá más importante de esas causas estuvo vinculada con la relocalización forzosa o desnaturalización de indios. En 1674 la corona española prohibió definitivamente la esclavitud de los «indios de guerra» de la Araucanía, que había estado legalizada desde la promulgación de una real cédula en 1608, aunque se había puesto

1 Archivo Nacional de Chile (ANC), Real Audiencia, 3003, 98v. Carta de Jerónimo de Quiroga a la Audiencia de Chile, Concepción, 24 de marzo de 1694. Otra copia en Archivo General de Indias (AGI), Chile, 125.

2 Rosales, 1910 [1672], 209.

3 En 1598 se produjo un levantamiento general de los nativos de la Araucanía, a quienes los españoles pretendían haber sometido desde mediados del siglo XVI, principalmente debido a los abusos cometidos por los encomenderos, que utilizaban la mano de obra indígena sobre todo para extraer oro de lavaderos (sobre la importancia del oro y del control de la mano de obra indígena ver Zavala, 2014). Cayeron en manos indias y fueron destruidas las siete ciudades fundadas al sur del río Bio-Bio, cuya población debió refugiarse en Concepción y en la isla de Chiloé. A partir de entonces, ese curso fluvial constituyó el límite fronterizo entre ambas sociedades. Francis Goicovich $(2002,2006,2007)$ ve allí el paso de la «etapa de conquista» a una «etapa de transición» caracterizada por la tensión entre los proyectos de misioneros y de vecinos y militares respecto de la dominación de los nativos. Sobre detalles de la rebelión y su época ver especialmente el clásico libro de Crescente Errázuriz (1881) y el trabajo de Goicovich (2002). Las negociaciones de paz de los años previos a la rebelión son vistos por Zavala, Dillehay y Payàs (2013) como una forma temprana de pacto fronterizo semejante a los parlamentos que se institucionalizarían en el siglo siguiente.

4 Barros Arana, 1999, 189-214. Una visión más semejante a la nuestra en Obregón, 2011. 
en práctica mucho antes. ${ }^{5}$ La prohibición de organizar malocas esclavistas ${ }^{6}$ generó la búsqueda de nuevas formas de hacerse de mano de obra indígena forzada o «indios de servicio». Ese contexto hace comprensibles los sucesos; un papel no menor cumplieron, de un lado, el plan de urbanización y reorganización espacial que tenía en mente el gobernador Tomás Marín de Poveda ${ }^{7}$ y, de otro, sus proyectos de enriquecimiento personal.

Habida cuenta del carácter ilegal de la esclavitud, Marín de Poveda aprovechó las denuncias por brujería para, mediante el castigo de desnaturalización y depósito, ejercer una política sistemática de castigo y de traslado poblacional cuyas finalidades económicas y políticas no pueden ocultársenos. El traslado forzoso de indígenas hacia las cercanías de las poblaciones españolas perseguía en definitiva el no tan secreto fin de instalarlas en proximidad de localidades que demandaban fuerza de trabajo, y por tanto seguía la «lógica de control y acercamiento de la mano de obra [a las poblaciones hispanas], puesto que la falta de "brazos" para el trabajo fue recurrente». ${ }^{8}$

Una segunda serie de causas gira en torno al comercio en la frontera. La conformación de un espacio fronterizo a partir de la impotencia hispana para consolidar la conquista llevó a que las alternativas de la violencia y la guerra convivieran con otros cursos de interacción que podrían considerarse en principio más pacíficos, como el intercambio comercial. Sin embargo, las formas que tomase el comercio también podían generar fricciones, y de hecho lo hicieron en el caso que estudiaremos, porque podía ocurrir que los ministros y oficiales reales acapararan en su favor el tráfico, sacando ventaja del escaso control que se ejercía sobre ellos, y obteniendo así un beneficio económico extraordinario en desmedro de los

5 La real cédula no se ejecutó hasta 1610, y entre 1610 y 1674 conoció épocas de derogación temporal, especialmente durante la Guerra Defensiva (1612-1626), catorce años en los que la disposición estuvo anulada por órdenes de Felipe III y el virrey marqués de Montesclaros. Un estudio de las prácticas del comercio esclavista durante el período de legalidad en Díaz, 2011.

6 Sobre la relación entre guerra y esclavitud indígena durante la Guerra de Arauco, ver el clásico trabajo de Jara, 1971. Sobre las malocas esclavistas del siglo XVII realizadas desde Chiloé, ver Urbina, 2009, 75-106.

7 Recordemos que en el reino de Chile el gobernador, además de cumplir funciones militares en su condición de capitán general, presidía la Audiencia de la jurisdicción.

8 Obregón y Zavala, 2009, 21. La desnaturalización estuvo lógicamente vinculada a la esclavitud desde el siglo XVI, puesto que los indígenas tomados como esclavos eran siempre relocalizados ya fuera en puntos de la frontera, en Chile central o en Perú, con vistas a su explotación económica (Valenzuela, 2011); sobre la relocalización en el valle de Aconcagua vinculada al servicio personal ver Contreras, 2013. 
pequeños comerciantes, que no tenían oportunidad de oponerse, y de los propios indígenas. La manipulación del intercambio también podía terminar motivando descontento y violencia en la frontera, en tanto se afectaran intereses y aquellos derechos que los nativos consideraran adquiridos para sí.

En febrero de 1694, la Audiencia de Chile, que había recibido varias denuncias al respecto, entre ellas las del ex-maestre de campo Jerónimo de Quiroga, decidió realizar una averiguación para informar al rey de las acusaciones que pesaban sobre Marín de Poveda. El enfrentamiento político entre el presidente y sus colaboradores (civiles, militares y eclesiásticos) por un lado, y los oidores de la Audiencia y ciertos oficiales fronterizos desplazados — como es el caso de Quiroga — por otro, nos permite visibilizar documentalmente un estado de cosas que en circunstancias distintas hubiese pasado inadvertido. El expediente que esa contienda generó ${ }^{9}$ arroja una luz esclarecedora sobre los juegos de intereses que pesaban en la región fronteriza, y que resultaron en el ejercicio de violencia contra los nativos, provocando su reacción.

Dos tipos de acusaciones inquietaban, entonces, al presidente y sus agentes. Una, vinculada con la política de desnaturalización de los indígenas: la ambición de reducirlos a pueblos y a misiones y de hacerse de trabajadores indígenas, aprovechando las enemistades internas y las acusaciones de brujería, llevó a castigar a muchas familias con la relocalización forzada, forjando en los nativos una reacción basada en el temor. La restante, con los intereses económicos en juego: el presidente sostenía un comercio con los indios monopolizándolo en su sola mano, autorizando solamente el conchavo $^{10}$ a personas de su confianza; también manejaba el comercio fronterizo a través de sus propias tiendas instaladas en todas las poblaciones de la frontera, impidiendo que otros comerciantes pudieran hacerlo por

9 AGI, Chile, 125, 1r-82r. «Expediente sobre las discordias entre la Audiencia y el Gobernador D.n Tomas Marín: años de 1661 à 1702». La implantación inicial de la Audiencia en Santiago implicó, como en otras partes de América, conflictos de competencia con las élites locales nucleadas en el cabildo, que pronto se reacomodaron (Valenzuela, 1998); pero la convivencia con los gobernadores no siempre fue tranquila, como ocurrió en este caso: ver las repetidas quejas de Marín de Poveda al rey sobre la oposición de la Audiencia a sus políticas en Pinedo, 2011, 147-150; sobre la rivalidad de Marín de Poveda con la Audiencia y con Jerónimo de Quiroga, ver Carvallo y Goyeneche, 1875 [1787], 200-204.

10 Así se denominaba en la época al intercambio comercial, en especial al que tenía lugar entre españoles e indios. Los españoles que se dedicaban a ese comercio interétnico eran llamados conchavadores. 
su cuenta. El contenido de las denuncias se ve complementado por las cartas escritas por Jerónimo de Quiroga contra la administración del gobernador, y una serie de documentos adicionales que ayudan a completar una imagen de lo que ocurría en aquellos años en el poco tranquilo Reino de Chile. Esas fuentes, de gran importancia tanto por la diversidad de actores que toman la palabra, como por su conocimiento de los asuntos fronterizos y el papel que en ellos jugaban, no han sido escasamente consideradas por los pocos autores que anteriormente se ocuparon del tema. La enemistad política que movía a los protagonistas ayuda a entender cuestiones que en la documentación oficial producida por el gobernador y sus colaboradores quedan interesadamente veladas, dificultando la comprensión de las motivaciones que movían a los indígenas. ${ }^{11}$

Trataremos las distintas cuestiones por separado. En primer lugar veremos qué decisiones políticas tomó Marín de Poveda respecto de los indígenas, en especial las vinculadas con el traslado compulsivo de población, cuál fue la reacción de los nativos, y cuáles las condiciones del ejército real para enfrentarla; luego repasaremos lo vinculado al manejo del comercio fronterizo; finalmente, en las conclusiones se ensaya una explicación que integra los aspectos más salientes de la rebelión y analiza cómo se conectaban entre sí.

\section{Reducción y violencia: la política fronteriza inicial de Tomás Marín de Poveda}

Tomás Marín de Poveda, nombrado presidente, gobernador y capitán general del Reino de Chile algunos años antes, tomó posesión del cargo en enero de 1692, trayendo consigo una corta tropa desde la península y tras haber pasado un año en Buenos Aires. Marín de Poveda llegó al cargo gracias no a una larga carrera administrativa, sino a la influencia de su familia en España, especialmente de un tío arzobispo. ${ }^{12}$ Una de sus primeras preocupaciones fue la situación de la frontera; en septiembre se trasladó a Concepción, llevando consigo el situado para pago de los sueldos atrasados de la tropa, y en diciembre hizo un parlamento en el tercio y plaza de

11 Esa documentación oficial, consistente sobre todo en cartas del propio Marín de Poveda al rey, fue utilizada extensamente por Diego Barros Arana (1999) y por Javier Pinedo (2011).

12 Sobre la familia y sus vínculos en la península, ver Andújar y Felices, 2011; Sánchez, 2011. 
Yumbel. Durante ese encuentro propuso a los indios reducirse a pueblos y misión, a lo que, según él, respondieron «todos los caciques unánimes y conformes con muy buena voluntad de admitir los ministros evangélicos y todo lo demás que se les propuso en orden a su reducción».$^{13}$ Fue justo en este momento que el término "parlamento» pasó a designar en Chile el «acto de concertación de paces entre españoles y mapuches». ${ }^{14}$

Marín de Poveda cumplía así, en principio, las órdenes que se le habían dado en la corte, donde se hacía caso a los misioneros que aseguraban que la reducción a pueblos y la evangelización eran la mejor y más duradera manera de pacificar a los nativos. El gobernador recortó la cantidad de oficiales militares, destinando esa porción del presupuesto ahorrado a sostener nuevas misiones. ${ }^{15}$ Esta ambición de reducción misional de los reche/ mapuche ${ }^{16}$ no sometidos por las armas se probó imposible durante todo el periodo colonial, y esta vez no fue la excepción: chocaba frontalmente con el modo de vida de aquellos, que defendía la dispersión de sus asentamientos y repudiaba visceralmente la concentración poblacional pretendida, en tanto comportaba además la sumisión al dominio de misioneros y autoridades civiles y militares.

La visión de los indígenas -e incluso de otros protagonistas españoles de la frontera- acerca de las políticas llevadas adelante por Marín de Poveda fue muy distinta de la perspectiva pretendidamente mesiánica con que el gobernador le escribía al rey. Según un oficial fronterizo, ya en aquel parlamento de Yumbel el capitán general invitó a los indios a convertirse y dejar la poliginia, cosa que no les gustó nada. Pero sobre todo intentó imponerles la prohibición de darse justicia a sí mismos según mandaba el

13 Carta de Marín de Poveda al rey, 26 de abril de 1693, citada en Barros Arana, 1999, 193.

14 Zavala, 2012, 154. Leonardo León (1992), que transcribió y analizó extensamente el texto producto del parlamento, lo consideró el inicio de un nuevo pacto colonial hispano-araucano; su estudio se interesa más por las novedades retóricas que allí aparecen que por el cumplimiento efectivo de las promesas mutuas realizadas en el parlamento.

15 Barros Arana, 1999, 195. No debe considerarse, sin embargo, que durante el siglo XVII chileno misiones y fuertes hayan estado separados, pues iban de la mano, lo mismo que la evangelización y el control militar de los indios, a quienes se aspiraba a mantener bajo la doble tutela de la Iglesia y del monarca: Valenzuela, 2011, 62-66.

16 Acerca de la compleja condición étnica de los indígenas de la región ha habido una discusión en los últimos tiempos: Boccara (1998) ha visto un proceso de etnogénesis que, a partir del contacto con los europeos, transformó a los antiguos reche del siglo XVI en mapuche para el siglo XVIII. Zavala, en cambio, rechaza esa doble designación enfatizando la ausencia de una franca ruptura identitaria y la evidente continuidad étnica que, a pesar de los cambios sufridos durante ese largo período, presentaron los mapuche históricos, en una línea que el propio pueblo mapuche reivindica hasta la actualidad (Zavala, 2003). 
ad mapu, ${ }^{17}$ proponiéndoles que denunciaran las infracciones a los españoles. De este modo y con la excusa de una conducta humanitaria, se deseaba asegurar la intervención colonial en los asuntos de los nativos y en particular el castigo de los brujos, pues «avia sido capitulado del Parlamento General se les administraría Justicia contra este Género de delinquentes». ${ }^{18}$

El rey aprobó la reducción de puestos militares para solventar las misiones. ${ }^{19}$ Pero además Marín de Poveda proyectaba una más amplia readecuación del espacio chileno, planificada en varias fases. Primero, sacar los fuertes de territorio indígena; ${ }^{20}$ luego, fundar villas o pequeñas poblaciones en el camino entre Santiago y Concepción, donde los españoles estaban muy dispersos en las haciendas: una de ellas fue Talca, a orillas del Maule, ${ }^{21}$ donde, como veremos, el gobernador mandó a asentar una parte de los indios desnaturalizados.

Dentro del marco de esos intentos de reforma, una de las decisiones de más graves consecuencias de la política fronteriza de Marín de Poveda fue el cambio en el elenco de encargados superiores de las relaciones interétnicas. Reemplazó al maestre de campo Jerónimo de Quiroga ${ }^{22}$ y al comisario de naciones ${ }^{23}$ Fermín de Villagrán por Alonso de Figueroa y Antonio de Soto Pedreros respectivamente. El presidente tomó esa decisión a pesar

17 El ad mapu era el conjunto de ideas, creencias y prescripciones tradicionales de los reche/mapuche. Entre sus reglas, una de las más notables era la que obligaba a los parientes de un muerto o agraviado a vengar el daño y buscar justicia para su grupo parental. Esa costumbre resistía la intervención de una fuerza externa y superior que la impartiera; en los grandes cacicatos de origen mapuche de las pampas, por ejemplo, recién en el siglo XIX se percibirá una tendencia en los caciques a concentrar en sus personas funciones judiciales aceptadas como tales por las partes en conflicto (Jiménez y Alioto, 2011).

18 ANC, Real Audiencia, 3003, 113r. Carta del cabildo de la Concepción al rey, Concepción, 20 de septiembre de 1695. En las citas documentales, las abreviaturas han sido desplegadas, se han separado las palabras que están escritas juntas, y se colocó mayúsculas en los nombres propios. Por lo demás, se mantuvo la grafía original de los documentos.

19 AGI, Chile, 159, sin foliación. Carta del rey a Tomás Marín de Poveda, Madrid, 21 de febrero de 1695 .

20 Petit-Breuilh, 2011, 136-137.

21 Díaz, 2011. La pequeña aldea de entonces fue el origen de la actual ciudad del mismo nombre.

22 Quiroga tuvo, a partir del desplazamiento de su cargo y del desacuerdo con las políticas fronterizas que impuso el nuevo presidente, una disputa política y personal con él que llegó a niveles muy ríspidos: Medina, 1906, 714-716; Barros Arana, 1999, 207 nota 28. Obregón piensa que es posible que la última parte de su obra histórica sobre la guerra de Chile (Quiroga, 1979 [1690]), referida a la segunda mitad del siglo XVII, le fuera secuestrada junto con otros papeles por orden del gobernador Marín de Poveda: Obregón, 2011, 109. Sobre la visión crítica de Quiroga respecto de las políticas seguidas en la frontera de Arauco, ver Espino, 2012.

23 Sobre esta institución ver Villalobos, 1982, 183-187. 
de que los indígenas habían advertido a las autoridades en distintas ocasiones que rechazaban terminantemente la designación de Figueroa, y sabiendo además que habían amenazado con alzarse en el caso de que se produjera. ${ }^{24}$ Tanto es así que ya el anterior gobernador Joseph de Garro se había abstenido de nombrarlo para el cargo, sabiendo de la mala fama que tenía entre los indios ${ }^{25}$ y aunque Marín de Poveda prometió lo mismo, no cumplió; los nativos aseguraban que

mienttras estubiese por Maestro de Campo dho Don Alonso de Figueroa, habian de bivir, con grande desconfiansa. Y que no havían de estar con quietud por los malos trattamienttos que les hacía dho Don Alonso de Figueroa y la poca palabra que tenía quando los llamaba. ${ }^{26}$

¿En qué consistían esos malos tratamientos? Aparentemente, Figueroa se las había ingeniado, con su maltrato, para disgustar a todos los nativos en general, incluso a los $\operatorname{costinos}^{27}$ que eran más propensos a aliarse con los españoles. Encontrándose de visita por la zona, «dio de palos a un Casique Prinsipal» que no salió lo suficientemente rápido a recibirle. ${ }^{28}$ Otros testigos aseguraron también que el propio presidente Marín de Poveda agredió a un líder indio presente en el parlamento de Yumbel: según uno de ellos, le «dio de guantadas», provocando que el agraviado se retirase disgustado. ${ }^{29} \mathrm{~A}$ un cacique costino que le reclamó mayores regalos y que le reprochó que «devía haser mas aprecio del dando alguna cossa a sus criados», don Tomás

le trato de borracho. Y le respondio que estava pobre y que benia a estas tierras a buscar su bida y no a Regalar. Y que replicandole dicho Casique que se devía hacer

24 AGI, Chile, 125, 10r. Declaración de Juan de Cisneros, «Expediente sobre las discordias...».

25 Ibidem, 45r. Testimonio del capitán Juan de Ugarte Urrispuro.

26 Ibidem, 61r. Declaración del alférez Joseph del Portillo. Lo mismo declararon otros testigos, como el vecino Juan Flores (Ibidem, 36v-37r) y el capitán Juan Francisco de Artasgos (Ibidem, 66v-67r).

27 Los españoles denominaban así a los indígenas situados sobre la costa del mar, al occidente de las montañas de Nahuelbuta; y llamaban llanistas a los grupos que ocupaban los valles y llanos interpuestos entre esas montañas y la cordillera de los Andes. Goicovich $(2006,2007)$ afirma que las grandes alianzas geoétnicas que en el siglo XVII (y aun más en el XVIII) conformarían los vutanmapus estaban esbozadas ya en la rebelión de 1598, pero solamente en ocasión de guerra; sería gradualmente durante la centuria siguiente que los vutanmapus se hicieron confederaciones visibles a los efectos de concertar la paz en los parlamentos. Sobre la organización sociopolítica mapuche ver Boccara, 1998 y Zavala y Dillehay, 2010.

28 AGI, Chile, 125, 23r. Testimonio del alférez Luis de Oría, «Expediente sobre las discordias...».

29 Ibidem, 55r. Testimonio de Joseph de Picabea. 
mucho Casso del, porque tenía seis mill lansas a su mandar, le dió de bastonasos dho Señor Don Thomas, le echo en el suelo y lo apuñetió y dio de coses, Y lo descalabro, y que dicho casique se fue muy sentido, Y diciendole a dicho Señor Don Thomas que afilase sus lansas Y que no quiso bajar dicho Casique a los Parlamentos que hubo despues de este Suseso. ${ }^{30}$

Jerónimo de Quiroga denunció también que los costinos se quejaban de los «malos tratamientos» del nuevo maestre de campo, entre los que incluían «averles hecho sembrar grandes cantidades de trigo en tres parajes de sus tierras para sus intereses con sus bueyes, arados y personas» sin pagarles ni darles alimento. ${ }^{31} \mathrm{Y}$ agregaban que Figueroa también los obligaba a pescar para él sin pagarles, trabajo por el que siempre se les había remunerado. ${ }^{32}$

Pero estos agravios, sean o no totalmente verdaderos, fueron solo complementarios de los sucesos que realmente generaron gran inquietud entre las reducciones indígenas, y que trataremos a continuación.

\section{Desnaturalizaciones y reacción indígena}

La esclavitud de los indios, uno de los motores principales del largo conflicto hispano-indígena en Chile, tuvo su período de práctica legal entre 1608 y 1674, aunque había comenzado antes de su legalización formal, y tendería a perdurar después, en tanto las élites chilenas no se resignaban a perder una fuente de mano de obra que les resultaba vital, ya que la población criolla pobre era todavía escasa y demasiado caros los esclavos negros. ${ }^{33}$

Una de las modalidades de perduración de la apropiación de mano de obra forzada fueron las denominadas ventas a la usanza del pays. En la práctica, se distorsionó una forma de intercambio mediante la cual un grupo indí-

30 Ibidem, 59v-60r. Declaración del alférez Luis de Fonseca.

31 ANC, Real Audiencia, 3003, 106v. Carta de Jerónimo de Quiroga a la Audiencia de Chile, Concepción, 20 de enero de 1694.

32 AGI, Chile, 125, 62v. Declaración del alférez Joseph del Portillo, «Expediente sobre las discordias...».

33 Según Valenzuela, hacia fines del XVII la acumulación y disponibilidad de una masa de peones mestizos empieza a hacer obsoleta la esclavitud indígena (Valenzuela, 2010, 236). De acuerdo con Contreras, luego de 1674 y alejado el fantasma de la esclavitud muchos indios amigos empezaron a pasar a tierras españolas para trabajar voluntariamente (Contreras, 2005-6, 16), proceso que continuó en el siglo XVIII. Las vías de ingreso de trabajadores indios fueron entonces dos: la forzada de antiguos esclavos o depositados que se quedaban, o el ingreso de trabajadores libres y voluntarios; a medida que avanzaba el tiempo, los segundos tendieron a predominar sobre los primeros (Contreras, 2005-6, 28-29). 
gena cedía temporaria y voluntariamente la fuerza de trabajo de una persona a los españoles a cambio de dinero, generándose luego un «mercado clandestino de compra-venta de personas, [...] basado en un sistema de apropiación cuasi forzada de mano de obra» ${ }^{34}$ que sin embargo encontraba justificación legal y moral. ${ }^{35}$ No obstante que la corona, ante los abusos cometidos, terminó prohibiendo la $u s a n z a,{ }^{36}$ en la práctica siguió existiendo - aunque en una escala menor- en algunos lugares incluso hasta fines de la colonia. ${ }^{37}$

A partir de 1674, cuando una real cédula prohibió la esclavitud indígena, se buscó otra manera de sacar indios de la tierra: los españoles se llevaban o sacaban o rescataban a los parientes de personas acusadas de ser kalkus — brujos — ${ }^{38}$ muchas veces con el estímulo de los soldados hispanos que reclamaban las piezas. También con esa excusa solía venderse a los niños huérfanos o a aquellas familias que quedaran sin parentela que las defendiera. Eso originó una cantidad enorme de conflictos entre agrupaciones indígenas,

porque los parientes de los muertos y vendidos por esclavos ofendidos, salian a la venganza, i, como entre ellos no hai justicia, sino que cada uno se la hace, se encendia gravisimo fuego entre las familias, i habia muertes, odios i bandos. ${ }^{39}$

Entre las distintas formas que los españoles encontraron para seguir procurándose mano de obra indígena, la desnaturalización ocupó, al menos en el momento que nos interesa, un lugar importante. Es cierto que lo había tenido desde la conquista, pues se complementaba con la esclavitud: después de su captura en maloca, el traslado de los indios esclavizados facilitaba su explotación económica allí donde los trabajadores fueran más requeridos (en muchas ocasiones, el destino era el Perú; en otras, el valle central chileno); por otro lado, desde el punto de vista político, el destierro

34 Villar y Jiménez, 2001, 39; ver Rosales, 1910 [1672], 204-205.

35 Valenzuela, 2010, 240.

36 Rosales, 1910 [1672], 205-206; Obregón y Zavala, 2009.

37 Sobre la continuidad de las prácticas esclavistas a pesar de la prohibición real ver Obregón y Zavala, 2009. En sus cartas, Jerónimo de Quiroga desnuda su continuidad a fines del siglo XVII, y relata cómo debió luchar para que el gobernador de Valdivia cumpliera con la devolución de las piezas tomadas ilegalmente. En las ciudades sureñas de Valdivia y Osorno, la costumbre siguió vigente hasta el final de la época colonial (Guarda, 1980), al igual que en las pampas y la cordillera (Villar y Jiménez, 2001).

38 Los mapuche creían que ninguna persona joven moría naturalmente, sino por causa de un daño que le era provocado por un brujo; siguiendo el admapu, que prescribía que el grupo de parientes de un muerto tenía la obligación de vengarlo, los brujos eran irremisiblemente ajusticiados por los grupos indígenas (Jiménez y Alioto, 2011).

39 Rosales, 1910 [1672], 201. 
parecía asegurar una ventaja bélica a los hispanos, al extrañar a los indígenas de las tierras que sin duda procuraban defender. ${ }^{40}$

La desnaturalización era, desde el punto de vista nativo, un castigo extremo: consistía en sacar a las personas individuales, familias o incluso grupos enteros de su lugar de origen — de donde habían nacido, es decir, de donde eran naturales - , de la contención de sus redes de parentesco, de sus lugares sagrados, ${ }^{41}$ y dejarlas indefensas en su nueva situación, como ilustra Rosales en nuestro segundo epígrafe. ${ }^{42}$ Según el jesuita, dos razones solían invocarse para justificar el destierro: una, facilitar su evangelización y reformar sus «bárbaras costumbres»; la otra, evitar que en sus tierras se alzaran «más facilmente y cuando quieren». ${ }^{43}$ En ambos casos, los hechos ocurridos hasta entonces desmentían ambos argumentos, y especialmente el segundo, ya que precisamente la saca de personas tendía a generar malestar y reacciones violentas por parte de los indios.

Ante la inexistencia formal de la institución esclavista y la ilegalidad del procedimiento maloquero ${ }^{44}$ de toma de piezas, el gobernador Marín de Poveda pergeñó una nueva política que combinaba prácticas anteriores con una novedosa e insidiosa intervención estatal en los asuntos indígenas, que articulaba denuncias por kalkutun y delaciones por intento de rebelión, con saca de personas y desnaturalización como castigo.

Según el testimonio del capitán Juan de Cisneros, el problema comenzó cuando Marín de Poveda envió al comisario de naciones Antonio de Soto Pedreros a visitar unas parcialidades de indios amigos. ${ }^{45}$ Soto empezó recorriendo las de la costa, donde algunos caciques acusaron a unas

40 Valenzuela, 2010, 244-249.

41 James Merrell (2000) ha hecho una descripción aleccionadora sobre las pérdidas que comportaba para un grupo el hecho de abandonar sus lugares tradicionales de habitación, en su caso refiriéndose a indígenas de Norteamérica que debieron mudarse a causa de las enfermedades introducidas y la consiguiente despoblación.

42 Un caso conocido en el Río de la Plata fue la relocalización de los indígenas de los valles calchaquíes luego de su derrota a mediados del siglo XVII: Carlón, 2007; Boixadós, 2011. Florencia Carlón profundiza en las consecuencias desarticuladoras de la relocalización para los quilmes, cuya población se redujo considerablemente en los primeros años a causa del cambio ambiental, las enfermedades y la explotación económica.

43 Rosales, 1910 [1672], 210.

44 El término maloca designaba a una incursión armada en territorio enemigo, realizada tanto por indios como por españoles, con el objetivo de obtener cautivos y otros recursos (como ganado), destruyendo además en lo posible los bienes económicos que facilitasen la reproducción del grupo rival. Se usaba también en el mismo sentido el verbo derivado maloquear.

45 En el siglo XVII chileno, se denominaba indios amigos a los que ayudaban a los españoles en la guerra, a manera de soldados étnicos: ver Ruiz-Esquide, 1993; Valenzuela, 2010, 237-241. Sobre la dicotomía amigos-enemigos, ver entre otros Obregón, 2008a. 
familias vecinas suyas de brujería, «diciendo que tenían benenos para matarlos»; con esa excusa, el capitán

los saco a ellos y a sus familias, desnaturalizándolos y que no obsttante que alegavan dhos yndios de no ser culpa de sus hijos, la que se les ymputaba se ejecutto el sacarlos de su naturaleza a ellos, sus hijos y sus mugeres poniendoles en diferenttes partes. ${ }^{46}$

Los «brujos» costinos fueron enviados «de la otra parte del río Maule» a 40 leguas de Concepción, es decir, en las cercanías de la recién fundada localidad de Talca, y con ellos se formó un pueblo en el que, según los vecinos notables de aquella ciudad, gozaban «del pasto espiritual con sumo provecho de sus almas», pero sobre todo y más importante, con provecho de los habitantes españoles de la región «quienes pagandoles su trabaxo se balen de ellos para el cultivo de sus labranças».47

Según otro testigo, las sacas en el butalmapu de la costa fueron al menos dos, una en la reducción de Arauco y la otra en Tucapel:

de orden de dicho Señor Don Thomas se sacaron de la reduccion de Arauco asta cosa de sinquenta yndios que no save este testigo donde paran oy y que despues segunda bes bio este testigo que traían desnaturalissados de la reduccion de Tucapel otra porcion de Yndios y que los an traydo de esta banda del rio de Maule menos algunas piessas que se reparttieron a diferentes personas en la ciudad de la Conzepcion. ${ }^{48}$

El comisario Soto siguió luego su camino por las reducciones de los llanos, donde también recibió quejas acerca de los brujos: de la delación surgió una imputación contra varias personas que fueron sometidas a juicio por haber hecho juntas secretas con el fin de matar a los indios amigos de los españoles. No nos detendremos en las interesantes circunstancias del juicio, que han sido objeto de una consideración inicial. ${ }^{49}$ Baste decir que

46 AGI, Chile, 125, 6v. Testimonio del capitán Juan de Cisneros, «Expediente sobre las discordias...». El cabildo de Concepción afirmó que fueron los propios caciques los que pidieron «que los extragesen de aquellos paises en castigo de sus delitos». ANC, Real Audiencia, 3003, 113r. Carta del cabildo de la Concepción al rey, Concepción, 20 de septiembre de 1695.

47 ANC, Real Audiencia, 3003, 113r. Carta del cabildo de la Concepción al rey, Concepción, 20 de septiembre de 1695 .

48 AGI, Chile, 125, 19v. Testimonio del alférez Luis de Oría, «Expediente sobre las discordias...». Según Quiroga, Soto Pedreros sacó «de las Provincias reducidas poco mas o menos de sesenta personas con pretexto de que las cabezas de estas familias eran brujos»; y que «de la sacada de estos dos últimos brujos resulto en los indios una gran desconfianza de los Ministros de este gobierno, porque es notorio a todos la mala Voluntad que tiene al Maestro de Campo general respecto de las hostilidades que hizo cuando los indios eran esclabos»: ANC, Real Audiencia, vol. 3003, 103r-103v. Carta de Jerónimo de Quiroga a la Audiencia de Chile, Concepción, 20 de enero de 1694.

49 Villar, Jiménez y Alioto, 2010. 
de los testimonios extraídos bajo tortura se supo que había un clima de descontento y de sublevación general, que «había corrido la flech $a »,{ }^{50}$ y que había planes de matar a los caciques amigos que se opusieran a una guerra abierta con los españoles; todo derivó en una serie de acusaciones que involucraban a otros caciques indígenas en el plan de sublevación armada.

Para solucionar el problema en que se encontraba, viéndose en vísperas de un levantamiento general, Marín de Poveda convocó a un nuevo parlamento en la ciudad de Concepción, contra la costumbre establecida de hacerlos en la frontera. Mil quinientos indios estuvieron durante quince días hospedados en las casas de los vecinos de la ciudad, y sintiéndose allí como en tierra extranjera no se consideraban en libertad de presentar quejas. En el momento de máxima tensión del encuentro, uno de los nativos imputados en el juicio acusó a dos de los caciques asistentes de promover el alzamiento y aunque ambos lo negaron, la atmósfera se hizo poco menos que irrespirable por el clima de mutua sospecha. Encerrado en la difícil situación política que en parte él mismo había creado y deseoso de superarla, Marín de Poveda decidió responsabilizar de la rebelión a los indios ayllacuriche, ausentes de la reunión. ${ }^{51}$

Los señalados ayllacuriche habían tenido sus razones para no hacerse presentes. Los inquietaba el maestre de campo Alonso de Figueroa, quien ya había ocupado ese mismo puesto durante la gestión de Juan de Henríquez (1670-1682), gobernador enormemente enriquecido mediante el tráfico de esclavos nativos. ${ }^{52}$ En aquella época, Figueroa sacó a los indios del cacique Ayllacuriche, ejecutado por los españoles en 1674, ${ }^{53}$ y los puso

50 Cuando se intentaba un levantamiento contra los españoles, quienes lo impulsaban enviaban a sus posibles aliados una flecha que simbolizaba la intención de iniciar la guerra; la aceptación del envío implicaba el acuerdo en participar, y quien acordaba podía a su vez promover la adhesión de otras reducciones, haciendo circular el objeto del mismo modo.

51 El etnónimo ayllacuriche (escrito en itálica en este artículo) responde a la costumbre española de nombrar a un grupo con referencia al cacique que los lideraba: en este caso, a los antiguos seguidores del cacique Ayllacuriche, del rewe de Viluco, se los denominaba con ese mismo nombre, convertido así en una etiqueta étnica.

52 Valenzuela, 2010, 235; Obregón (2011, 113-114), a partir de la obra de Córdoba y Figueroa, calcula en 175.000 pesos la fortuna acumulada por Henríquez, que fue protector de Marín cuando este servía en la frontera y posiblemente representara su modelo político a seguir. José Toribio Medina, sin adjudicarla exclusivamente al tráfico de piezas, eleva la suma a 700.000 pesos, y afirma que fue «el gobernador que más rico salió del reino»: Medina, 1906, 403.

53 Según Rosales, Ayllacuriche no tenía la actitud decididamente hostil que le adjudicaban los españoles, sino que a veces no salía a negociar por el temor, bien fundado, de que los cristianos atacarían a su gente para tomar piezas; de hecho, cuando ofreció la paz le secuestraron a los mensajeros diplomáticos enviados y lo maloquearon: Rosales 1910 [1672], 191, 211. 
en depósito sesenta leguas adentro del territorio español, dando lugar al temor y odio que le profesaban.

La institución del depósito había dado ocasión para que Henríquez urdiera un subterfugio en beneficio de los hacendados españoles para esquivar la cédula de prohibición de la esclavitud de 1674. El gobernador debía obedecer la orden real de no hacer piezas en lo sucesivo, pero tenía el problema de que los hacendados se resistían a desprenderse de sus esclavos. Su solución de compromiso fue dejarlos en depósito, o sea «en poder de sus dueños, recibiendo salario por su trabajo, hasta que se resolviera su situación». ${ }^{44}$ Según Eugene Korth, sin embargo, los indios depositados eran «puestos bajo la custodia de algún hacendado que accediera a vigilar a los prisioneros a cambio del privilegio de aprovecharse de su trabajo». ${ }^{55} \mathrm{El}$ hacendado debía compensarlos por la labor que realizaran, pero eso sólo implicaba darles comida, casa y vestido, y velar por su buena conducta, y no incluía el pago de un salario. ${ }^{56}$ En 1686, Carlos II aprobó el plan de depósitos y en 1688 estableció que los indios no debían ser incorporados a encomiendas existentes, sino que quedarían bajo la custodia de quienes hubieran sido designados por diez años, durante los cuales tributarían sólo al real tesoro. ${ }^{57}$ Sin embargo, la corona aceptó en algunos casos que «los esclavos depositados se agregaran a las encomiendas existentes o se formaran con ellos otras nuevas, si eran numerosos» ${ }^{58}$ Además, nuevos depósitos de indios se solicitaron sobre naturales apresados en la guerra (o hijos de éstos), exigiéndose constancia escrita acerca de la acción en que hubieren sido tomados, o la declaración de testigos de los hechos. ${ }^{59}$ Por último, en 1703, Felipe V ordenó la cesación de todos los depósitos de indios

54 Hanisch, 1981.

55 Korth, 1968, 201.

56 Entonces, el sistema de depósito y custodia «era poco más que una variación del servicio personal, pero con la importante distinción de que los prisioneros asignados al hacendado español no le pertenecían en el sentido en que sus indios de encomienda sí lo hacían. Teóricamente al menos, meramente le eran confiados hasta que la corona o bien aprobara el sistema o bien ordenase alguna otra disposición para con los hostiles tomados en la guerra» (Korth, 1968, 201-202) La medida se justificaba argumentando la conveniencia de que los indios no volvieran a sus tierras como mandaba la cédula, porque entonces abandonarían para siempre la cristiandad. El control ejercido por los hacendados no era absoluto: podían ser privados de los servicios de los indios, si estos se quejaban a los corregidores por malos tratos.

57 Korth, 1968, 203.

58 Valenzuela, 2010, 236. Rosales aprobaba los depósitos como forma alternativa a la esclavitud, que condenaba fuertemente: Rosales 1910 [1672], 245.

59 González, 1966, 25. 
y que quedasen libres todos los que hubieren sido de esa especie, dejando sin ninguna fuerza las asimentaciones o pueblos que de ellos se hubiese hecho en las estancias del Reino y que tanto los indígenas de encomiendas como los de depósitos y yanaconas, fueran reducidos a parajes y sitios comodos. ${ }^{60}$

La decisión generó lamentos y oposición en las autoridades locales, que de nuevo arguyeron que ni españoles ni criollos tenían otro medio de mantenerse si no era con el trabajo de los indios, «porque el cultivo de la tierra cesa donde no hay quien tome el azadón y el arado», y a lo impracticable de procurarse el trabajo de negros y mulatos por su escasez y alto costo en relación a la corta riqueza de las haciendas. Los verdaderos motivos económicos de la resistencia se ocultaban luego ideológicamente con la excusa de procurar el bien de los propios nativos, que se verían perjudicados por la medida por su poco amor al trabajo («que es la cosa que más aborrecen») y su reticencia a abrazar la fe cristiana, «siendo su adoración, el vino, las mujeres y la ociosidad»; además, se les daría la oportunidad de escapar y unirse a los fronterizos. ${ }^{61}$ Cuando se extinguió el sistema de depósitos de indios, sin embargo, muchos de ellos no retornaron a sus tierras sino que «se asentaron cerca de sus antiguos lugares de residencia forzosa, esta vez como hombres libres». ${ }^{62}$

Pero ese no fue el caso de los ayllacuriche, que por cierto no se hallaban tan a gusto en tierras españolas. Muchos de ellos se escaparon, reuniéndose con indios fugados de otros depósitos:

en unas tierras apartadas de esta Ciudad sesenta leguas quedaron algunas familias de la reduccion de Ayllacuriche a quien quito la vida el Señor Don Juan Enrriquez y depositó toda su jente y a estas familias se an agregado algunos indios fugitivos del deposito en que estaban puestos. ${ }^{63}$

Los indios de esa reducción no olvidaban que cuando Figueroa había sido gobernador de Purén durante el mando de Henríquez,

saco injustamente y debajo del seguro de su palabra a estos Ayllacuriches, y siendo los que oi se hallan en esta reducion delincuentes, y el Maestre de Campo el arbitro de las armas de este Exercito justamente desconfiaron de salir a su llamado porque siempre se presume que será malo en aquel genero de mal que uno tiene de costumbre. ${ }^{64}$

60 Ibidem, $15-16$.

61 Ibidem, 26.

62 Contreras, 2005-2006, 8.

63 ANC, Real Audiencia, vol. 3003, 104r. Carta de Jerónimo de Quiroga a la Audiencia de Chile, Concepción, 20 de enero de 1694.

64 Idem. 
Fue así que, desconfiando justamente de las intenciones de Figueroa dados sus antecedentes en la materia, doscientos indios se excusaron de concurrir a Concepción,

porque son fugitivos del deposito de Aillacuriche y como delinquentes temieron la prisión, especialmente viendo en el puesto de Maestre de campo Governador a Don Alonso de Figueroa que fue el que Antes debajo de la fee publica los apreso según es su común sentir. ${ }^{65}$

Pero ante las acusaciones cruzadas de las cuales finalmente poco de importancia pudo obtenerse sobre las intenciones de rebelión - y aprovechando que la ausencia daba pábulo a la sospecha de alzamiento-, Marín de Poveda envió sacar a los renuentes ayllacuriche con las armas, aprovechando que eran pocos y sospechando que no generarían resistencia. Para ello comprometió además a los indios amigos a que

se obligasen a desnaturalisar dichos yndios de Aylla Curichi y que yría con dhos yndios el comisario de naciones Pedreros y que de echo fue el dicho Pedreros con dichos yndios cassiques y saco asta ciento y quarenta familias poco mas o menos las quales pusieron en la reduccion del fuertte de San Christobal de yndios Amigos que esta media legua del tercio de Yumbel. ${ }^{66}$

Se produjo entonces un desacuerdo con los indios amigos respecto de qué hacer con esas ciento cuarenta familias: finalmente se procedió como quería el gobernador y en lugar de repartirlos se ubicaron en los llanos todos juntos, en la reducción de San Cristóbal, «con grave perjuicio» de los indios amigos y españoles por sus «depravadas costumbres» e infidelidad. ${ }^{67}$ Esa reducción y misión de indios amigos estaba unos kilómetros al norte del Bio-Bio, muy cerca de Yumbel, una de las principales guarniciones militares españolas de la frontera, con lo cual se aseguraba una estricta vigilancia armada de los recién llegados. ${ }^{68}$

Atónitos ante lo que estaba sucediendo, algunos indios protestaron, solicitando que las autoridades españolas liberaran a los presos, porque eran sus parientes; pero no fueron escuchados. La insensata conducta del gobierno dio motivo a los demás para alzarse, sospechando que la saca de

65 Ibidem, 95v-96r. Carta de Jerónimo de Quiroga a la Audiencia de Chile, Concepción, 24 de marzo de 1694.

66 AGI, Chile, 125, 8v. Declaración de Juan de Cisneros, «Expediente sobre las discordias...».

67 Ibidem, 21v. Declaración del alférez Luis de Oría. $2008 b$.

68 Ver datos sobre la localización y el volumen de las guarniciones fronterizas en Obregón, 
familias se estaba transformando en una política habitual con cualquier excusa, y que por lo tanto el riesgo de sufrirla los alcanzaba a todos.

El carácter decisivo de las recurrentes desnaturalizaciones en el malestar de los indios y en el levantamiento general constituye una convicción casi unánime de los testigos ${ }^{69} \mathrm{El}$ alférez Joseph del Portillo brindó una información más completa sobre la cuestión, que confirma que el traslado había tenido el propósito de acercar indios a los poblados españoles para aprovecharse de su trabajo:

Dijo que en quantto a las causas del dicho alsamiento lo que a oydo decir es, que con prettesto de brujerías se sacaron muchos yndios, de las Reduciones de Maquegua y sus contornos, Y que algunos de dhos indios [...] estavan en Talca, a la orilla del Río de Maule, de esta partte de la Ciudad de Santiago, Y asimesmo oyo decir, que otros de dhos yndios se quedaron a Travajar, en las aciendas del maestro de Campo Don Alonso de Figueroa, Y que otros se havían repartido a diferenttes personas y aviendo pasado este testigo a la tierra adentro despues de susedido el alsamiento oyo decir algunos Capitanes y soldados de las plasas que dho alsamiento, se havia orijinado del sentimientto con que quedaron los yndios por causa de haver sacado los que ya quedan referidos, y el ttemor con que bivían de que se ysiese con ellos, lo mesmo. ${ }^{70}$

Resulta notorio que la relocalización de gente no fue únicamente un castigo penal: también comportó una manera de hacerse de mano de obra forzada de manera gratuita para el propio maestre de campo y personas de su confianza y, acaso mediante pago, para otros vecinos de la zona. A la vez, favorecía la población de la recién fundada localidad de Talca, uno de los desvelos del gobernador.

Pero la desnaturalización aplicada a los indígenas acusados, lejos de ser ejemplificadora como pretendían los españoles, resultó contraproducente, porque expandió entre los nativos el temor de que cualquiera pudiera recibir idéntico castigo. Quiroga descarta otras hipótesis sobre las causas del alzamiento y terminantemente afirma que la causa fue

ver estos miserables [indios] que sacaban familias enteras co[n] titulo de brujos para transportarlos a otras partes y condenarlos a perpetua servidumbre, y temer cada uno que con sus personas, y familia se haria mañana lo mesmo, y ver cuan a proposito eran los nuevos cabos del Exercito para estas operaciones. ${ }^{71}$

69 AGI, Chile, 125, 37r. «Expediente sobre las discordias...». El vecino Juan Flores dijo haber visto a los indios desnaturalizados «de esta otra banda del río Maule». El testigo alférez Fonseca sostuvo que el levantamiento se debió a las desnaturalizaciones y a haber hecho parlamentos en Yumbel y en Concepción.

70 Ibidem, 60v-61r. Declaración del alférez Joseph del Portillo.

71 ANC, Real Audiencia, 3003, 109r. Carta de Jerónimo de Quiroga a la Audiencia de Chile, Concepción, 20 de enero de 1694. 
Según Carvallo y Goyeneche, el discurso de Millapal, el cacique de Maquegua que encabezó la rebelión, se afincaba con fuerza en la idea de rechazar el destierro y la intervención española en las cuestiones indígenas:

ellos vivian en sus tierras sin apetecer otras, i que en ellas tenian cuanto necesitaban para pasar la vida, i que el gobernador desistiese del empeño de estraerlos de los montes donde residian gustosos en pleno i libre uso de las costumbres que heredaron de sus predecesores; i porque no seria facil hacerles abandonar sus machis, sus brujos i sus adivinos, de quienes se valian para la curacion de sus dolencias, como los españoles de sus médicos..$^{72}$

Liderados por Millapal, una cantidad de entre 1.500 y 3.000 indios tomaron las armas y sorprendieron en mala situación al ejército español, al que no hicieron más daño únicamente porque extrañan «la cercanía de sus casas y el amor de sus mugeres, y de la Chicha, y lo principal porque no tienen cabesa [líder]». ${ }^{73}$ Los 3.000 indios calculados por Quiroga no eran todos maqueguanos ni seguidores de Millapal, que sólo tenía 600 lanzas; en efecto, si 200 más eran de los ayllacuriche, puede sospecharse que la alianza de los rebeldes abarcaría muchas más reducciones, próximas y lejanas. ${ }^{74}$

Mientras el comisario de naciones Soto Pedreros sacaba a los ayllacuriche, los rebeldes, ya en abierta actitud bélica, se dirigieron en su búsqueda para matarlo y como no lo encontraron ultimaron al capitán español

72 Carvallo y Goyeneche, 1875 [1787], 196.

73 ANC, Real Audiencia, 3003, 108v. Carta de Jerónimo de Quiroga a la Audiencia de Chile, Concepción, 20 de enero de 1694.

74 Ibidem, 97r. Carta de Jerónimo de Quiroga a la Audiencia de Chile, Concepción, 24 de marzo de 1694. De hecho, por lo que había logrado averiguar en el juicio antes mencionado, Marín de Poveda debió sospechar que algo así podría ocurrir, porque los acusados que participaron en las reuniones preparatorias del abortado alzamiento hablaban allí de un amplio arco de alianzas que partiendo de Viluco (la tierra de Ayllacuriche) reunía prácticamente a todos los llanistas, a algunos rewes de la costa e incluso a pehuenches de ultracordillera. Quienes impulsaban el alzamiento venían trabajando esa alianza desde hacía cuatro años, invocando agravios que giraban sobre todo alrededor de las ventajas y la soberbia de los indios amigos de los españoles, que llevaban a trabajar a los mocetones, quienes muchas veces morían de enfermedades introducidas: «estos Caziques amigos de españoles nos tienen Sujetos y abasallados y en qualquier Cossa que Se ofreze ellos se lleban toda la honrra y estimazion y no se haze Casso de nosotros y Si ay alguna faena ellos son los que Suben a Cauallo y bienen a sacar nuestros mozetones para llevarlos al trauajo y ellos se llevan los provechos y agasajos de los españoles y a nosotros nos tratan como a perros y Sin hazer casso de mi Como Si fueramos Sus esclavos» (Declaración de Naguelquirque, en «Juicio a Juan Pichuñan y otros», Biblioteca Nacional de Chile, Manuscritos Medina, 323, 149-150). El hecho de que en cuatro años no hubieran podido aun realizar el levantamiento general que sí precipitó y catalizó la actuación del gobernador habla claramente sobre la importancia de su intervención, aunque también marca que los indígenas tenían razones previas de descontento con los españoles y sus aliados nativos. 
de la reducción. Marín de Poveda, decidido a hacer guerra, despachó una expedición al mando de Soto Pedreros con 2.500 indios amigos de la costa y Purén con una escuadra de arcabuceros. El comisario encontró a los alzados en el río Quepe, y en su irreflexivo impulso por batirlos se lanzó imprudentemente a cruzarlo, ocasión que aquellos aprovecharon para terminar con su vida y la de tres caciquillos amigos, determinando la retirada de los españoles.

El gobernador debió sustituirlo nuevamente por Villagrán, quien se abocó a reorganizar un ejército muy debilitado como consecuencia de varios factores confluyentes. En realidad, la situación castrense había sido precaria durante todo el XVII; los soldados vivían miserablemente del situado, y algunos de la toma de piezas en la guerra mientras duró la esclavitud. ${ }^{75}$ En época de Marín de Poveda, se agregó el problema de la falta de pan para el mantenimiento de la tropa, porque «abiendose enbiado a Lima el pan con que se abia de mantener el egercito no hubo con que sustentarle». ${ }^{76}$ Francisco Reynoso, en su carta a la Audiencia, opina que debió haberse salido a campaña para componer las cosas, pero agrega que el presidente no pudo hacerlo «por aber enviado el trigo a vender a Lima y consertandose con el probehedor racionero en plaza a los Soldados no aviendo donde comprar el pan para sustento». ${ }^{77}$ En efecto, la cosecha peruana había fracasado y Marín de Poveda vio un negocio en ello. No dudó entonces en poner en riesgo el abasto local, vendiendo casi toda la producción cerealera de Chile, a pesar de que el Cabildo se había opuesto a que la realizara. ${ }^{78}$

Otra acusación señala que el gobernador vendió trigo por su cuenta y que, por lo tanto, hubo que abonar en metálico el situado, por falta de cereal. En consecuencia, los soldados debieron adquirir en plata su sustento, obligada conducta que siempre estimulaba maniobras especulativas para despojarlos. ${ }^{79}$

75 Vargas, 1993; Contreras, 2011.

76 ANC, Real Audiencia, 3003, 97v. Carta de Jerónimo de Quiroga a la Audiencia de Chile, Concepción, 24 de marzo de 1694.

77 Ibidem, 101r-101v. Carta de Francisco Reynoso a la Audiencia de Chile, Concepción, 12 de enero de 1694. Otra copia en AGI, Chile, 125.

78 Obregón, 2011.

79 Precisamente por esa razón, el virrey del Perú optaba de ordinario por enviar «el situado con ropa cada año, para que este Exercito se vista, porque en plata no es para el soldado, sino para quien lo empeña»: ANC, Real Audiencia, 3003, 109v. Carta de Jerónimo de Quiroga a la Audiencia de Chile, Concepción, 20 de enero de 1694. Otra copia en AGI, Chile, 125. 
La falta de caballadas aptas para la guerra también constituyó un factor perjudicial. Eran momentos en que los campos de los españoles se dedicaban más a la cría de mulas exportables al Perú que a la de yeguarizos. Quiroga recomendaba

cortar la cria de mulas en este obispado... porque no ai otro decurso para montar el exercito sino la cria de potros y criandose solo ellos no eran los bastantes para estar bien montados, y asi se conpraban todos los años dos mil caballos con el situado; oi salen de aqui nuebe o dies mil mulas cada año y de este interes se aplica la atencion y si no salieran quedaban otros tantos rosines..$^{80}$

Siendo la caballería un arma fundamental al punto de considerársela la llave misma de la guerra, constituía una mala noticia que el ejército estuviera «desmontado porque toda la aplicasion se pone en el comersio de las mulas y asi faltaban caballos con que moberse». ${ }^{81}$

\section{El monopolio del conchavo con los indios y las tiendas fronterizas de Marín de Poveda}

Si la desnaturalización fue el móvil principal del conflicto, y la pobre situación del ejército un elemento facilitador, otra de las causas que los testigos invocaron para explicar el malestar y el consiguiente levantamiento de los indios radicaba en que las autoridades prohibieron a los conchavadores españoles pasar a comerciar a la tierra de indios, salvo con una autorización expresa que sólo se daba a ciertas personas adictas al gobernador, en especial religiosos y lenguaraces o capitanes de amigos. ${ }^{82}$

Según testificó el alférez Luis de Oría, Marín de Poveda tenía prohibido a los vecinos de Concepción el comercio con los naturales, requisando las mulas y las mercancías a los que se atrevieran a pasar tierra adentro. Sólo lo permitía a los lenguas oficiales de sus plazas, que introducían

80 ANC, Real Audiencia, 3003, 99v. Carta de Jerónimo de Quiroga a la Audiencia de Chile, Concepción, 24 de marzo de 1694.

81 Ibidem, $97 \mathrm{v}$.

82 En el Reino de Chile se instituyó, en época de Henríquez, la figura de los capitanes de amigos, españoles que vivían entre los indígenas e informaban a las autoridades españolas acerca de sus novedades: Villalobos, 1982, 187-195. Su conocimiento de la lengua indígena los hacía mediadores lingüísticos de primer orden, lo mismo que ocurría con los misioneros; del lado rioplatense, en cambio, los mediadores hispano-criollos fueron menos abundantes. 
vino y otros géneros. ${ }^{83}$ Para algunos declarantes, todos ellos dependían del presidente, quien en última instancia detentaba el monopolio. ${ }^{84}$ La nueva política comercial perjudicaba a la vez a los vecinos penquistas, que no podían usufructuar el negocio mercantil, y a los indios, porque al ir «todo por una sola mano $»^{85}$ no conseguían un precio justo para sus productos. Era el momento en que el negocio de los esclavos declinaba y comenzaba a establecerse entonces el clásico comercio fronterizo aún más asentado en el siglo siguiente. Los españoles vendían vino, ropa y objetos de metal de su propia producción o importados de la península, y compraban ponchos y mantas de manufactura indígena, que alcanzaban buen valor en los mercados coloniales. ${ }^{86} \mathrm{El}$ impulso que llegó a tomar ese intercambio, en un momento posterior, preocupó a las autoridades eclesiásticas y civiles porque en pago de los ponchos indígenas los españoles vendían sus propios caballos, debilitando las defensas militares hispanas y a la vez mermando la base imponible de los diezmos. ${ }^{87}$

El capitán Antonio de Erize confirmó que el presidente tenía «embarazado» o dificultado el intercambio, según lo había oído de un comerciante. El alférez Luis de Fonseca pensaba también que eran las limitaciones al comercio «de vino y otros géneros» lo que enojaba los nativos, pues «a nadie se da lizencia para el de todos los becinos y soldados de la fronttera sino es a los curas de los tercios a los quales se permite comerciar solo con tres cargas de vino». ${ }^{88} \mathrm{El}$ alférez Joseph del Portillo explicó que durante el mando de Jerónimo de Quiroga en la frontera los conchavadores entraban libremente las veces que quisieran a la tierra de indios. Pero con posterioridad a que Marín de Poveda y el maestre de campo Figueroa prohibieran el comercio a través de un bando, comenzó a requerirse para ejercerlo una venia oficial que las autoridades eran remisas a otorgar. El hecho de que sólo después de que ocurriera el levantamiento

83 La venta de vino a los indios alcanzó una importancia tal para los españoles que un siglo después las autoridades soñaban con que generaría en los nativos una profunda dependencia y que esta eventualmente les reportaría su definitiva sumisión; además, daba a los productores vinícolas del Penco una salida segura a su producción, que no encontraban en el mercado colonial peruano: Alioto y Jiménez, 2010, 190-194.

84 AGI, Chile, 125, 10r. Declaración de Juan de Cisneros, «Expediente sobre las discordias...».

85 Ibidem, 10r. Declaración de Juan de Cisneros. Ibidem, 56r. Declaración de Luis de Fonseca.

86 León, 1991, 88-93; Boccara, 1998, 295-302.

87 León, 1991; Alioto y Jiménez, 2010, Alioto, 2011, pp. 153-157. dias...».

88 AGI, Chile, 125, 56r. Declaración de Antonio de Erize, «Expediente sobre las discor- 
se relajase el control entrañó un reconocimiento implícito de que esa fue una de sus causas. ${ }^{89}$

El monopolio del comercio interétnico se complementaba con el que tenía lugar en las plazas y tercios fronterizos, del que eran víctimas, en este caso, los soldados y vecinos de la frontera del Bio-Bio. El procedimiento utilizado para hacer llegar el situado hasta aquellas lejanas dependencias imperiales continuamente propiciaba las arbitrariedades cometidas con la tropa, a raíz de la manipulación de sus sueldos. ${ }^{90}$ El capitán Juan Francisco de Hartazgos testimonió que durante el mandato de Marín de Poveda todo el ejército se aprovisionaba en las tiendas que dependían del presidente, mientras que los demás comerciantes locales no se atrevían a involucrarse en el negocio porque sospechaban que no se les pagaría en tiempo y forma. ${ }^{91}$

Según Juan de Cisneros, el gobernador tenía tiendas en Concepción, Arauco y la Estancia del Rey, pero Luis de Oría aseguró que Marín de Poveda no sólo las tenía allí, sino también en Tucapel, Purén, Yumbel, Chillán y Maule: lo sabía como testigo directo, porque fue a llevar ropa a esos lugares. Es posible que parte de esas tiendas las manejasen dos parientes que el presidente trajo consigo a Chile, su hermano Antonio y su sobrino José, de quienes se sabe que eran comerciantes en Concepción y que fueron acusados de contrabando por el sucesor de Marín de Poveda, Francisco Ibáñez de Peralta. ${ }^{92}$ En los puntos de la frontera en que había corregidores, Marín de Poveda les mandaba mercancías para vender de su cuenta; y hasta en Chiloé vendía vino, ropa y lana para hacer mantas, quitando el comercio a los locales.

El vecino Juan Flores dijo conocer de qué manera abastecía el gobernador sus tiendas: había mandado a Lima una recua de mulas que volvió cargada con una parva de ropa para vender por importe de 200.000 pesos. En cambio, Erize sospechaba que transportó mercaderías desde Buenos Aires cuando viajó a Chile para asumir su cargo, luego de permanecer allá un año.

89 Ibidem, 61r-62r. Declaración de Joseph del Portillo.

90 Para evitar los abusos y la inseguridad de los traslados por mar desde el Callao, se propuso que el situado viajase por tierra desde Potosí, pero ello provocó una lentitud mucho mayor en el tránsito y no solucionó los problemas de abastecimiento: ver Barros Arana, 1999. En la plaza de Valdivia, donde las partidas llegaban obligatoriamente por la vía marítima dado el carácter aislado de la ciudad, los gobernadores también tuvieron participación en ese tipo de negocios, consistentes en quedarse con la plata de los sueldos a cambio de mercancías sobrevaluadas que los soldados no tenían más remedio que adquirir: Alioto, 2011, 143-145.

91 AGI, Chile, 125, 67r-67v. Declaración de Juan Francisco de Artasgos, «Expediente sobre las discordias...».

92 Silva, 2007, 198. 
El capitán Juan de Ugarte, por último, agregaba que el presidente no sólo monopolizaba la venta de mercancías a los indios, sino también la compra, acaparando todos los géneros negociados, al punto de que no se conseguían.

\section{Desenlace y conclusiones}

La rebelión fue finalmente sofocada por una gran campaña militar en octubre de 1694. El propio Marín de Poveda se puso a la cabeza de los 1.600 soldados españoles y 2.000 indios amigos que había reunido, y logró que los nativos se allanasen a participar de un parlamento realizado en Choque Choque hacia fines de aquel año. ${ }^{93}$ Todos los caciques principales presentes, incluido Millapal, protestaron obediencia y juraron que no habían sido parte de la conjura. Pero según el relato del gobernador, uno de ellos admitió que los mocetones habían matado españoles porque tenían «miedo a que los sacasen de sus tierras». ${ }^{94}$

Que la amenaza de desnaturalización tuvo un papel central es indudable. Hasta Diego Barros Arana, que elabora una versión de los hechos favorable al gobernador y a su política, admite que «es posible también que en las medidas tomadas por los españoles entrase por mucha parte el deseo de sacar prisioneros que llevar a las estancias del norte, castigo que se daba a los llamados culpables»..$^{95}$

La saca de familias tuvo al menos dos motivos. Uno fue el de favorecer personalmente a Marín de Poveda y a sus oficiales y amigos, que se aprovecharon del trabajo de algunos de los indios desplazados para sus propias haciendas. Otro formó parte del plan más general de urbanización promovido por el gobernador, que a su vez estaba vinculado a la labor misional: los clérigos habían convencido a la corte, y también al presidente de la Audiencia, de que eran muy eficaces para la conversión de los

93 Un resumen de lo tratado en ese parlamento en Contreras, 2010, 82-83; cf. Obregón, 2011.

94 Carta de Marín de Poveda al rey, en Barros Arana 1999, 199. De todo el expediente que citamos (que se cierra con un sellado de enero de 1695), el único testigo que invoca otras causas para la rebelión es Sebastián de Espinoza afirma que, según le dijo a su vez el lengua Andrés de Yllescas, la rebelión se debió a la planchada de calles que les hicieron hacer a los indios, y a que el gobernador suspendió las mitas de indios y fomentó el ocio... Pero cuando le hicieron otras preguntas de la sumaria, confirmó que sí se sacó gente de «arriba» al otro lado del Maule, que el presidente sí tenía estancado el comercio, y que explotaba sus propias tiendas en la frontera: AGI, Chile, 125, 31r y ss. «Expediente sobre las discordias...». Mocetones eran los jóvenes varones en condiciones de combatir.

95 Barros Arana, 1999, 197. 
indios (exhibían como prueba de ello la gran cantidad de bautismos realizados), pero que lo serían aún más si tanto cristianos como indios se reducían a pueblos, que era la mejor manera de adoctrinarlos. Según aseguraba Carvallo un siglo después de los sucesos, el «éxito» de los misioneros había persuadido a Marín de Poveda de que «era llegado el tiempo de reducir a los indios de Chile a civilizacion, i se propuso quitarles los hechiceros i adivinos, sacarles de los montes i unirles en las llanuras de sus provincias», ${ }^{96}$ con las consecuencias que ya conocemos.

Ante la resistencia a seguir las políticas impuestas, los nativos reprimidos por insurrectos fueron acusados, como siempre, de una doble infidelidad: a la «verdadera religión» cristiana que no querían abrazar, y a la corona, a quien se supone que debían subordinarse sin miramientos. La sola decisión de no concurrir a un parlamento, considerada suficiente prueba de rebeldía, hizo recaer sobre los ausentes el castigo de la saca y destierro. Pero aun cuando se insistía en reprochar a los remisos la típica inconstancia del bárbaro, en realidad la razón principal de su desconfianza y temor radicó en la inconsulta novedad introducida por los españoles. El desacostumbrado señalamiento de un punto de reunión fuera de la frontera constituyó una sorpresiva anomalía en el trato inter-étnico que despertó en los convocados lógicas prevenciones y les hizo concebir la inconveniencia de asistir.

Marín de Poveda intentó una nueva política decididamente intrusiva sobre las poblaciones indígenas no sometidas al control colonial. Su intervención sobre los asuntos judiciales nativos por causa de brujerías promovió la delación y generó la posibilidad de vengar agravios por interpósita persona, dando a los españoles la oportunidad de castigar a aquellos que los indios amigos considerasen sus enemigos o a quienes quisieran perjudicar por venganza o por cualquier otro motivo. Esa intervención generó un desequilibrio y una gran suspicacia. La división entre indios amigos e indios enemigos, hostiles o rebeldes se hizo más pronunciada a partir de esta nueva política, porque mientras los primeros se sentían a salvo y gozaban de los beneficios de la amistad con los españoles, los demás se veían en riesgo de perder incluso sus propias casas y el lugar que habitaban, además de la libertad, en caso de ser acusados por los anteriores.

El episodio se muestra como una bisagra entre dos siglos, que tendrán como eje principal dos problemas distintos, aunque desde luego no haya un corte abrupto entre ellos. Durante el XVII, la principal preocupación de los

96 Carvallo y Goyeneche, 1875 [1787], 196. 
españoles en su relación con los nativos fue la de hacerse de mano de obra esclava para compensar la escasez de brazos que los afligía. Buena parte de las autoridades civiles y militares, e incluso los soldados, hicieron fortuna mediante el comercio de esclavos indígenas. Acabada la esclavitud formalmente permitida, se buscaron otros medios de procurársela, entre los que no se descartaba el uso de castigos como la desnaturalización y la saca de familias enteras hacia tierras de españoles.

En la centuria siguiente, en cambio, si bien la preocupación por la mano de obra indígena seguirá vigente y también las formas para-legales e ilegales de conseguirla, el énfasis del vínculo irá virando hacia las relaciones comerciales y el intercambio. ${ }^{97}$ Aunque exista la tentación de llamar pacíficas a estas últimas - y lo son, comparadas con situaciones de guerra abierta-, no resultaban serlo tanto si se toma en cuenta que ese intercambio creaba a su vez considerables fricciones. Sin duda que el comercio de piezas o las ventas a la usanza constituían situaciones generadoras de violencia en sí mismas; pero aun cuando se tratase de vino o ponchos las reacciones podían sobrevenir al no respetarse la voluntad de las partes, los protocolos de interacción o, como en este caso, cuando su acaparamiento o interferencia por parte de las autoridades estatales era tomado por una ofensa. La preocupación de Marín de Poveda por multiplicar las villas y pueblos de la región y asentar allí a mayor cantidad de gente como manera de adelantar la civilización también es parte de las tendencias que se impondrían en el siglo de las luces.

Eso no debe ocultar que parte de las motivaciones que movían al gobernador eran económicas. Unas lo eran en un sentido general: sus decisiones se dirigían a facilitar a los españoles que gobernaba el acceso a la imprescindible mano de obra indígena. Otras, únicamente respecto de sus finanzas personales y familiares: estaba intentando recuperar los fondos que él mismo y su familia habían invertido en su ascenso fulgurante, y no omitió medio que pudiera llevarlo en ese sendero. ${ }^{98}$

97 Un resumen del intercambio hispano-indígena en el siglo XVIII en Zavala, 2011, 217-233.

98 Barros Arana ya había sugerido que su carrera no ameritaba que se lo nombrara en cargo tan elevado, y que posiblemente su ascenso se debía a la venalidad: Barros Arana, 1999, 190. Ángel Sanz Tapia encontró que Marín de Poveda había comprado el cargo por 44.000 pesos, una alta cifra que no volvió a repetirse en el caso de Chile (Sanz, 2009, 164, 232, 323, 326). Andújar (2011, 81-88) analiza el posible origen del dinero que permitió semejante pago, debido principalmente a la colaboración de la familia, liderada por su tío Bartolomé González de Poveda, presidente de la Audiencia de La Plata y luego arzobispo; Obregón $(2011,106)$ sugiere además que quizá el mismo Marín de Poveda hubiera hecho fortuna con el tráfico de esclavos indios durante la gobernación de Henríquez. 
Sin embargo, los objetivos del laborioso Marín de Poveda se mostraban incompatibles con los medios de que disponía. Careciendo de los suficientes, no debió intentar la pacificación de los indios por la fuerza, ni emprender una política francamente disruptiva respecto del estado de cosas heredado. Pero así lo hizo y en oportunidad de la rebelión, el ejército no estuvo en condiciones de salir en campaña por falta de pan y de caballada. Y si se salvó de soportar consecuencias peores fue únicamente porque en un momento dado los nativos decidieron no contraatacar.

Por añadidura, también sus distintos propósitos eran inconciliables entre sí. Instalar misiones que tomaran el lugar de la milicia y recortar los puestos de oficiales militares fronterizos, pero a la vez sacar familias indígenas para poblar con ellas tierras españolas, y crear por añadidura un monopolio del comercio fronterizo en su favor constituían metas provocativas que no podían buscarse simultáneamente sin desatar la reacción de los nativos.

No obstante, Marín de Poveda presentó una versión exitosa de su manejo de las relaciones con los indios, y el despliegue de tropas y el parlamento de 1694 fueron interpretados entonces y después como un triunfo; pero no faltaron quienes señalaran que las paces establecidas eran indignas, porque el gobernador las firmó para tapar sus errores anteriores y evitar que se hablase

de la muertte que avian dado al Comisario General de naciones Pedreros y al capitan Miguel de Quiroga y que no vbiesse misiones ni se ablase de Brujos, Y que las pases havian deser por el tiempo que quisiesen dhos indios. ${ }^{99}$

A pesar de su visión triunfalista, el presidente debió dar marcha atrás con muchas de las disposiciones que tomó para pacificar el país y sólo su capacidad de neutralizar enemigos e interceptarles la correspondencia, ${ }^{100}$ así como la importancia de sus vínculos en España lo salvaron de una peor suerte y fama. La sentencia recaída en el juicio de residencia liberó de culpa y cargo al ya finado ex-presidente; todos los testimoniantes hablaron maravillas de su actuación, de la fundación de nuevas misiones, y de cómo había pacificado a los indios mediante los dos parlamentos que realizó. ${ }^{101}$

99 AGI, Chile, 125, 22r. Declaración del alférez Luis de Oría, «Expediente sobre las discordias...».

100 Sobre las persecuciones y el secuestro de correspondencia ver las cartas citadas de Francisco Reynoso y Jerónimo de Quiroga, en ANC, Real Audiencia, 3003 y AGI, Chile, 125.

101 AGI, Escribanía de la Cámara de Justicia, 941A, en especial 185 y ss. «Residencia a don Tomás Marín de Poveda, por Gabriel Cano de Aponte su sucesor, en 1718, fenecida en 1733». 
Sus influencias en la corte lograron contrarrestar las acusaciones, y en Chile nadie parecía recordar, o todos simularon olvidar, los graves sucesos del año 1693, cuando la gente de la tierra se sublevó, no sin motivos, contra los vicarios del rey español.

Recibido el 21 de noviembre de 2013

Aceptado el 22 de septiembre de 2014

\section{Bibliografía}

Alioto, Sebastián L. y Jiménez, Juan Francisco: «"Pues para ello les quedaba livertad". Comercio e interdependencia en las fronteras meridionales del imperio español (segunda mitad del siglo XVIII)», Barbaroi, 32, Santa Cruz do Sul, 2010, 178-204.

Alioto, Sebastián L.: Indios y ganado en la frontera. La ruta del río Negro (17501830), Rosario, Prohistoria/Centro de Documentación Patagónica, 2011.

Andújar Castillo, Francisco: «Tiempo de venalidad. Tomás Marín de Poveda y la venta de cargos en Indias», en Andújar Castillo, Francisco y Giménez Carrillo, Domingo Marcos (eds.), Riqueza, poder y nobleza: los Marín de Poveda, una historia familiar del siglo XVII vista desde España y Chile, Almería, Editorial Universidad de Almería, 2011, 79-92.

Andújar Castillo, Francisco y Felices de la Fuente, María del Mar: «El poder de una familia: los Marín de Poveda, de Lúcar (Almería) a Chile en el siglo XVII», en Andújar Castillo, F. y Giménez Carrillo, D. M. (eds.), Riqueza, poder y nobleza: los Marín de Poveda, una historia familiar del siglo XVII vista desde España y Chile, Almería, Editorial Universidad de Almería, 2011, 15-32.

Barros Arana, Diego: Historia General de Chile, tomo V, Santiago de Chile, Editorial Universitaria/Centro de Investigaciones Diego Barros Arana, 1999.

Boccara, Guillaume: Guerre et ethnogenèse Mapuche dans le Chili Colonial. L invention du soi, París, L Harmattan, 1998.

Boixadós, Roxana: «El fin de las guerras calchaquíes. La desnaturalización de la nación yocavil a La Rioja (1667)», Corpus, Archivos Virtuales de la Alteridad Americana, I-1, Buenos Aires, 2011.

Carlón, Florencia: «La reducción "Exaltación de la Cruz de los indios Quilmes": un caso de relocalización étnica en Pampa a fines del siglo XVII», Mundo Agrario. Revista de Estudios Rurales, VIII- 15, La Plata, 2007, disponible electrónicamente en http://www.mundoagrario.unlp.edu.ar/article/view/ v08n15a07/1022. 
Carvallo y Goyeneche, Vicente: «Descripción histórico-jeográfica del Reino de Chile», II [1787], en Colección de historiadores de Chile y documentos relativos a la historia nacional, IX, Santiago de Chile, Imprenta de la Estrella de Chile, 1875.

Contreras Cruces, Hugo: "“Siendo mozeton o güeñi salió de su tierra a vivir entre los españoles": migración y asentamiento mapuche en Chile central durante el siglo XVIII, 1700-1750», Historia Indígena, 9, 2005-2006, 7-32.

Contreras Cruces, Hugo: «Una enfermedad vieja y sin remedio: la deserción en el Real Ejército de la Frontera de Chile durante el siglo XVII», Fronteras de la Historia, 16-2, Bogotá, 2011, 443-468.

Contreras Cruces, Hugo: «Crisis y cambios en las comunidades originarias del valle de Aconcagua (Chile), 1580-1650», Población y Sociedad, 20-1, San Miguel de Tucumán, 2013, 11-40.

Contreras Painemal, Carlos: Los tratados celebrados por los Mapuche con la Corona Española, la República de Chile y la República de Argentina, tesis doctoral, Freien Universität Berlin, 2010, disponible electrónicamente en http://www.diss.fu-berlin.de/diss/receive/FUDISS_thesis_000000025635 consulta 16.5.2014.

Díaz Blanco, José Manuel: «La empresa esclavista de don Pedro de la Barrera (1611): una aportación al estudio de la trata legal de indios en Chile», Estudios Humanísticos. Historia, 10, León, 2011a, 55-70.

Díaz Blanco, José Manuel: «Política urbana de Tomás Marín de Poveda en Chile: las fundaciones de Rengo y Talca en su contexto», en Andújar Castillo, F. y Giménez Carrillo, D. M. (eds.), Riqueza, poder y nobleza: los Marín de Poveda, una historia familiar del siglo XVII vista desde España y Chile, Almería, Editorial Universidad de Almería, 2011b, 163-176.

Espino López, Antonio: «Aforismos militares y guerra del Arauco: las Memorias de los sucesos de la guerra de Chile de Jerónimo de Quiroga», Anuario de Estudios Americanos, 69-2, Sevilla, 2012, 601-626.

Errázuriz, Crescente: Seis años de la historia de Chile (23 de diciembre de 15989 de abril de 1605): memoria histórica, Santiago de Chile, Imprenta Nacional, 1881.

Goicovich, Francis: «La etapa de la conquista (1536-1598): origen y desarrollo del "Estado indómito"», Cuadernos de Historia, 22, Santiago de Chile, 2002, 53-110.

Goicovich, Francis: «Alianzas geoétnicas en la segunda rebelión general: génesis y dinámica de los vutanmapus en el alzamiento de 1598», Historia, 39-1, Santiago de Chile, 2006, 93-154.

Goicovich, Francis: «Entre la conquista y la consolidación fronteriza: dispositivos de poder hispánico en los bosques meridionales del Reino de Chile durante la etapa de transición (1598-1683)», Historia, 40-2, Santiago de Chile, 2007, 311-332. 
González Pomés, María Isabel: «La encomienda indígena en Chile durante el siglo XVIII», Historia, 5, Santiago de Chile, 1966, 7-103.

Guarda, Gabriel: «El servicio de las ciudades de Valdivia y Osorno, 1770-1820», Historia, 15, Santiago de Chile, 1980, 67-178.

Hanisch Espíndola, Walter: «Esclavitud y libertad de los indios de Chile, 16081696», Historia, 16, Santiago de Chile, 1981, 5-65.

Jara, Álvaro: Guerra y sociedad en Chile, Santiago de Chile, Editorial Universitaria, 1971.

Jiménez, Juan Francisco y Alioto, Sebastián L.: «El sistema judicial indígena como expresión de complejidad política (Pampas y Patagonia norte, mediados del siglo XIX)», Journal de la Société des Américanistes, 97-2, París, 2011, 45-74.

Korth, Eugene H.: Spanish Policy in Colonial Chile: The Struggle for Social Justice, 1535-1700, Stanford, Stanford University Press, 1968.

León, Leonardo: «El pacto colonial hispano-mapuche y el parlamento de 1692», Nütram, 30, Santiago de Chile, 1992, 27-53.

Medina, José Toribio: Diccionario biográfico colonial de Chile, Santiago de Chile, Imprenta Elzeviriana, 1906.

Merrell, James H.: «The Indians New World: the Catawba Experience», en Mancall, Peter y Merrell, James H. (eds.), American Encounters. Natives and Newcomers from European Contact to Indian Removal, 1500-1850, New York/London, Routledge, 2000, 27-37.

Obregón Iturra, Jimena Paz: «Aproximación crítica al pensamiento dicotómico "indios amigos" versus "indios enemigos" bajo el gobierno del Marqués de Baides, Chile, 1639-1646», Revista CUHSO, 15-2, Temuco, 2008a, 25-30.

Obregón Iturra, Jimena Paz: «Concepciones hispanas en torno a un territorio disputado en Chile: Araucano-mapuches y españoles durante el siglo XVII», Cultura y representaciones sociales, 2-4, México, 2008b, 72-93.

Obregón Iturra, Jimena Paz: «Claves de un encumbramiento exitoso y de una política indígena emprendedora: los Parlamentos hispano-indígenas de Tomás Marín de Poveda (Chile, 1692-1694)», en Andújar Castillo, F. y Giménez Carrillo, D. M. (eds.), Riqueza, poder y nobleza: los Marín de Poveda, una historia familiar del siglo XVII vista desde España y Chile, Almería, Editorial Universidad de Almería, 2011, 93-114.

Obregón Iturra, Jimena Paz y Zavala Cepeda, José Manuel: «Abolición y persistencia de la esclavitud indígena en Chile colonial: estrategias esclavistas en la frontera araucano-mapuche», Memoria Americana, XVII-1, Buenos Aires, 2009, 7-31.

Petit-Breuilh Sepúlveda, María Eugenia: «Relaciones fronterizas hispano-indígenas en la época del capitán general Marín de Poveda (Chile, 1692-1700)», en Andújar Castillo, F. y Giménez Carrillo, D. M. (eds.), Riqueza, poder y 
nobleza: los Marín de Poveda, una historia familiar del siglo XVII vista desde España y Chile, Almería, Editorial Universidad de Almería, 2011, 115-137.

Pinedo, Francisco Javier: «Tomás Marín de Poveda (1650-1703), gobernador de Chile: pensamiento político y contexto histórico», en Andújar Castillo, F. y Giménez Carrillo, D. M. (eds.), Riqueza, poder y nobleza: los Marín de Poveda, una historia familiar del siglo XVII vista desde España y Chile, Almería, Editorial Universidad de Almería, 2011, 139-162.

Quiroga, Jerónimo de: Memorias de los sucesos de la Guerra de Chile, Santiago de Chile, Editorial Andrés Bello, 1979 [1690].

Rosales, Diego de: «Manifiesto apolojético de la esclavitud del Reino de Chile, por el Padre Diego de Rosales, de la Compañía de Jesus...», en Amunátegui, Miguel L., Las encomiendas indígenas de Chile, II, Imprenta Cervantes, Santiago de Chile, 1910 [1672], 183-272.

Ruiz-Esquide Figueroa, Andrea: Los indios amigos en la frontera araucana, Santiago de Chile, DIBAM, 1993.

Sánchez Ramos, Valeriano: «Una poderosa red familiar del Alto Almanzora: los Marín de Poveda y sus alianzas», en Andújar Castillo, F. y Giménez Carrillo, D. M. (eds.), Riqueza, poder y nobleza: los Marín de Poveda, una historia familiar del siglo XVII vista desde España y Chile, Almería, Editorial Universidad de Almería, 2011, 33-76.

Sanz Tapia, Ángel: ¿Corrupción o necesidad? La venta de cargos de gobierno americanos bajo Carlos II, Madrid, CSIC, 2009.

Sanz Tapia, Ángel: «Andaluces en cargos políticos hispanoamericanos (16741700)», en Gutiérrez Escudero, Antonio y Laviana Cuetos, María Luisa (coords.), Estudios sobre América: siglos XVI-XX, Sevilla, Asociación Española de Americanistas, 2005, 613-632.

Silva Vargas, Fernando: «Los gobernadores como agentes estructuradores de la sociedad chilena en los siglos XVII y XVIII», Boletín de la Academia Chilena de la Historia, 116-1, Santiago de Chile, 2007, 177-218.

Urbina Carrasco, María Ximena: La frontera de arriba en Chile colonial: Interacción hispano-indígena en el territorio entre Valdivia y Chiloé e imaginario de sus bordes geográficos, 1600-1800, Valparaíso/Santiago, Ediciones Universitarias de Valparaíso/Centro de Investigaciones Diego Barros Arana, 2009.

Valenzuela Márquez, Jaime: «Conflicto y equilibrios simbólicos ante un nuevo actor político: la Real Audiencia en Santiago desde 1609», Cuadernos de Historia, 18, Santiago de Chile, 1998, 115-138.

Valenzuela Márquez, Jaime: «Esclavos mapuches. Para una historia del secuestro y deportación de indígenas en la colonia», en Gaune, Rafael y Lara, Martín (eds.), Historias del racismo y la discriminación en Chile, Santiago de Chile, Uqbar Editores, 2010, 225-260. 
Valenzuela Márquez, Jaime: «Revisitando el "indigenismo” jesuita: en torno a los "bárbaros" de Arauco, la guerra y la esclavitud mapuche en el siglo XVII», en Chamorro, Graciela; Cavalcante, Thiago Leandro Vieira y Gonçalves, Carlos Barros (eds.), Fronteras e identidades. Encontros e Desencontros entre Povos Indígenas e Missôes Religiosas. XIII Jornadas Internacionais sobre as Missôes Jesuíticas, Saô Bernardo do Campo, Nhanduti Editora, 2011, 61-79.

Vargas Cariola, Juan Eduardo: «Estilo de vida en el ejército de Chile durante el siglo XVII», Revista de Indias, LIII-198, Madrid, 1993, 425-457.

Villalobos R., Sergio: «Tipos fronterizos en el ejército de Arauco», en Villalobos R., Sergio et al., Relaciones fronterizas en la Araucanía, Santiago de Chile, Ediciones Universidad Católica de Chile, 1982, 177-221.

Villar, Daniel y Jiménez, Juan Francisco: «"Para servirse de ellos”: cautiverio, ventas a la usanza del pays y rescate de indios en las pampas y Araucanía (siglos XVII-XIX)», Relaciones de la Sociedad Argentina de Antropología, XXVI, Buenos Aires, 2001, 31-55.

Villar, Daniel; Jiménez, Juan Francisco y Alioto, Sebastián L.: «Satánicas argucias. El proceso a Juan Pichuñan y otros, Yndios rebeldes, en la frontera de la Concepción de Chile a fines del siglo XVII», Revista de la Escuela de Antropología, XVI, Rosario, 2010, 65-75.

Zavala Cepeda, José Manuel: «Relaciones interétnicas e identidad indígena: el caso mapuche en el contexto colonial», en Actas del Cuarto Congreso Chileno Antropología, 19 al 23 de noviembre 2001, Santiago de Chile, Colegio de Antropólogos/LOM Ediciones, 2003, Tomo I, 392-397.

Zavala Cepeda, José Manuel: Los mapuches del siglo XVIII. Dinámica interétnica $y$ estrategias de resistencia, Temuco, Ediciones Universidad Católica de Temuco, 2011.

Zavala Cepeda, José Manuel: «Los parlamentos hispano-mapuches como espacios de mediación», en Payàs, Gertrudis y Zavala, José Manuel (eds.), La mediación lingüístico-cultural en tiempos de guerra: cruce de miradas desde España y América, Temuco, Universidad Católica de Temuco, 2012, 151-162.

Zavala Cepeda, José Manuel: «The Spanish-Araucanian World of the Purén and Lumaco Valley in the Sixteenth and Seventeenth Centuries», en Dillehay, Tom (ed.), The Teleoscopic Polity: Andean Patriarchy and Materiality, New York, Springer, 2014, 55-73.

Zavala Cepeda, José Manuel y Dillehay, Tom: «El "Estado de Arauco" frente a la conquista española: estructuración sociopolítica y ritual de los araucanomapuches en los valles nahuelbutanos durante los siglos XVI y XVII», Chungará, 42-2, Arica, 2010, 433-450.

Zavala Cepeda, José Manuel; Dillehay, Tom y Payàs, Gertrudis: «El requerimiento de Martín García Óñez de Loyola a los indios de Quilacoya, Rere, Taruchina y Maquegua de 1593, testimonio oficial de parlamentos hispano-mapuches tempranos», Memoria Americana, 21-2, Buenos Aires, 2013, 235-268. 